\title{
KONSUMSI DALAM EKONOMI ISLAM
}

\author{
Oleh: Azwar Hamid \\ Dosen Jurusan Ekonomi Syariah Fakultas Ekonomi dan Bisnis Islam \\ IAIN Padangsidimpuan
}

\begin{abstract}
Consumption is an individual process to fulfill human daily needs. In Islam, it is one of primer needs which is called as maslahat. Islamic Economy manage human in completing their needs, for example the object must be halal, the way to get the object must follow the syariah and the transaction must be completed with the commandments and requirements.

Keywords: consumtion, transaction, islamic economy
\end{abstract}

\section{A. Pendahuluan}

Pengeluaran konsumsi masyarakat adalah salah satu variabel makro ekonomi yang dilambangkan "C". Konsep konsumsi yang merupakan konsep yang di Indonesiakan dalam bahasa Inggris "Consumption", merupakan pembelanjaan yang dilakukan oleh rumah tangga ke atas barang-barang akhir dan jasa-jasa dengan tujuan untuk memenuhi kebutuhan dari orang-orang yang melakukan pembelanjaan tersebut atau juga pendapatan yang dibelanjakan. Bagian pendapatan yang tidak dibelanjakan disebut tabungan, dilambangkan dengan huruf "S" inisial dari kata saving. Apabila pengeluaran-pengeluaran konsumsi semua orang dalam suatu negara dijumlahkan, maka hasilnya adalah pengeluaran konsumsi masyarakat negara yang bersangkutan.

Pembelanjaan masyarakat atas makanan, pakaian, dan barang-barang kebutuhan mereka yang lain digolongkan pembelanjaan atau konsumsi. Barangbarang yang di produksi untuk digunakan oleh masyarakat untuk memenuhi kebutuhannya dinamakan barang konsumsi. Kegiatan produksi ada karena ada yang mengkonsumsi, kegiatan konsumsi ada karena ada yang memproduksi, dan kegiatan produksi muncul karena ada gap atau jarak antara konsumsi dan produksi. Prinsip dasar konsumsi adalah "saya akan mengkonsumsi apa saja dan jumlah beberapapun sepanjang: anggaran saya memadai dan saya memperoleh kepuasan maksimum“. 
Banyak alasan yang menyebabkan analisis makro ekonomi perlu memperhatikan tentang konsumsi rumah tangga secara mendalam. Alasan pertama, konsumsi rumah tangga memberikan pemasukan kepada pendapatan nasional. Di kebanyakaan negara pengeluaran konsumsi sekitar 60-75 persen dari pendapatan nasional. Alasan yang kedua, konsumsi rumah tangga mempunyai dampak dalam menentukan fluktuasi kegiataan ekonomi dari satu waktu ke waktu lainnya. Konsumsi seseorang berbanding lurus dengan pendapatannya.).

Semakin besar pendapatan seseorang maka akan semakin besar pula pengeluaran konsumsi.

\section{B. Pembahasan}

\section{Konsumsi dan Fungsi Konsumsi}

Konsep konsumsi, yang merupakan konsep yang di Indonesiakan dari bahasa inggris "Consumtion". Konsumsi adalah pembelanjaan atas barangbarang dan jasa-jasa yang dilakukan oleh rumah tangga dengan tujuan untuk memenuhi kebutuhan dari orang yang melakukan pembelanjaan tersebut. Teori Konsumsi adalah teori yang mempelajari bagaimana manusia / konsumen itu memuaskan kebutuhannya dengan pembelian / penggunaan barang dan jasa. Sedangkan pelaku konsumen adalah bagaimana ia memutuskan berapa jumlah barang dan jasa yang akan dibeli dalam berbagai situasi.

Pembelanjaan masyarakat atas makanan, pakaian, dan barang-barang kebutuhan mereka yang lain digolongkan pembelanjaan atau konsumsi. Barangbarang yang di produksi untuk digunakan oleh masyarakat untuk memenuhi kebutuhannya dinamakan barang konsumsi.

Fungsi konsumsi adalah suatu kurva yang menggambarkan sifat hubungan di antara tingkat konsumsi rumah tangga dalam perekonomian dengan pendapatan nasional (pendapatan disposebel) perekonomian tersebut. Fungsi konsumsi dapat dinyatakan dalam persamaan $:{ }^{1}$ i. Fungsi konsumsi ialah $: \mathrm{C}=\mathrm{a}+\mathrm{By}$. Dimana a adalah konsumsi rumah tangga ketika pendapatan nasional adalah 0 , b adalah kecondongan konsumsi marginal, $\mathrm{C}$ adalah tingkat konsumsi dan $\mathrm{Y}$ adalah tingkat pendapatan nasional. 
Ada dua konsep untuk mengetahui sifat hubungan antara pendapatan disposebel dengan konsumsi dan pendapatan diposebel dengan tabungan yaitu kosep kecondongan mengkonsumsi dan kecondongan menabung. Kecondongan mengkonsumsi dapat dibedakan menjadi dua yaitu kecondongan mengkonsumsi marginal dan kecondongan mengkonsumsi ratarata. Kencondongan mengkonsumsi marginal dapat dinyatakan sebagai MPC (berasal dari istilah inggrisnya Marginal Propensity to Consume), dapat didefinisikan sebagai perbandingan di antara pertambahan konsumsi $(\Delta \mathrm{C})$ yang dilakukan dengan pertambahan pendapatan disposebel $(\Delta \mathrm{Yd})$ yang diperoleh. Nilai MPC dapat dihitung dengan menggunakan formula : MPC $=Y d . C \Delta$

Kencondongan mengkonsumsi rata-rata dinyatakan dengan APC (Average Propensity to Consume), dapat didefinisikan sebagai perbandingan di antara tingkat pengeluaran konsumsi (C) dengan tingkat pendapatan disposebel pada ketika konsumen tersebut dilakukan (Yd). Nilai APC dapat dihitung dengan menggunakan formula : $\mathrm{APC}=Y d$.

Kecondongan menabung dapat dibedakan menjadi dua yaitu kencondongan menabung marginal dan kecondongan menabung rata-rata. Kecondongan menabung marginal dinyatakan dengan MPS (Marginal Propensity to Save) adalah perbandingan di antara pertambahan tabungan $(\Delta S)$ dengan pertambahan pendapatan disposebel $(\triangle \mathrm{Yd})$. Nilai MPS dapat dihitung dengan menggunakan formula : MPS $=Y d . S \Delta$.

Kecondongan menabung rata-rata dinyatakan dengan APS (Average Propensity to Save), menunjukan perbandingan di antara tabungan (S) dengan pendapatan disposebel (Yd). Nilai APS dapat dihitung dengan menggunakan formula $:$ APS $=Y d . S$.

\section{Prinsip Teori Konsumsi ${ }^{2}$}

1. Barang (goods) yang di konsumsi mempunyai sifat semakin banyak akan semakin besar manfaatnya. Dengan demikian, jika sesuatu yang bila dikonsumsi semakin banyak justru mengurangi kenikmatan hidup (bad) tidak dapat didefinisikan sebagai barang, misalnya penyakit. 
2. Utilitas (utility) adalah manfaat yang diperoleh seseorang karena ia mengkonsumsi barang, Dengan demikian Utilitas merupakan ukuran manfaat (kepuasan) bg seseorang karena mengkonsumsi barang. Keseluruhan manfaat yang diperoleh konsumen karena mengkonsumsi sejumlah barang disebut dengan Utilitas total (Total Utility) Utilitas marjinal (marginal utility) adalah tambahan manfaat yang diperoleh karena menambah satu unit konsumsi barang tertentu.

3. Pada teori Utilitas berlaku Hukum Pertambahan Manfaat yang Makin Menurun (The law of Diminishing marginal utility) yaitu bahwa awalnya sesorang konsumen mengkonsumsi satu unit barang tertentu akan memperoleh atambahan Utilitas (manfaat) yang besar, akan tetapi tambahan unit konsumsi barang tersebut akan memberikan tambahan Utilitas (manfaat yang semakin menurun, dan bahkan dapat memberikan manfaat negatif. Dengan kata lain, Utilitas marjinal (MU) mula-mula adalah besar, dan semakin menurun dengan meningkatnya unit barang yang dikonsumsi.

4. Pada teori Utilitas berlaku konsistensi preferensi, yaitu bahwa konsumen dapat secara tuntas (complete) menentukan rangking dan ordering pilihan (preference, choice) diantara berbagai paket barang yang tersedia. Konsep ini disebut dengan Transitivity dan rasionalitas. Misalnya, jika A lebih disuka dari $\mathrm{B}$ atau $\mathrm{A}>\mathrm{B}$, dan $\mathrm{B}$ lebih disukai dari $\mathrm{C}$ atau $\mathrm{B}>\mathrm{C}$, maka harus berlaku A lebih disuka dari $\mathrm{C}$, atau $\mathrm{A}>\mathrm{C}$.

5. Pada teori Utilitas diasumsikan bahwa konsumen mempunyai pengetahuan yang sempurna berkaitan dengan keputusan konsumsinya. Mereka dianggap (diasumsikan) mengetahui persis kualitas barang, kapasitas produksi, teknologi yang digunakan dsb.

\section{Teori Konsumsi Dalam Perbaikan Ekonomi}

Teori konsumsi dan tingkat perbaikan ekonomi. 2 hal ini sempat dikemukan oleh presiden SBY saat krisis ekonomi sempat hinggap dan terus hinggap sehinga menjadi masalah tersendiri bagi perekonomian Indonesia bangsa Indonesia secara keseluruhan.Tingkat konsumsi seperti apa ? Waktu itu Presiden SBY memalui 
pemerintahannya sempat megajukan usulan peningkatkan aktivitas konsumsi dalam ngeri untuk memulihkan perekonomian, secara tidak langsung industri ekonomi dalam negri akan tumbuh dengan baik. ${ }^{3}$

Konsumsi seperti apa ? pertanyaan yang terus berulang, banyak pihak yang mengatakan bahwa daya beli masyarakat Indonesia rendah. Kalau begitu apa ukurannya ? di sektor mana saja ? Sebuah jawaban yang belum saya ketahui. Tapi sekarang mari kita lihat apakah sebenarnya daya beli mayarakat Indonesia rendah.

Pernyataan daya beli masyarakat Indonesia sebenarnya tidak lah rendah jika hal ini dihitung dari kebutuhan sekunder.Yang masih membinggungkan sekarang ini ialah masyarakt Indonesia sepertinya tidak lagi bisa membedakan yang mana kebutuhan primer atau kebutuhan sekunder, sebuah teori mengatakan "Lihat saja sekarang hampir dari satu setengah populasi penduduk Indonesia sudah punya mobile communication atau bahasa sederhananya adalah handphone atau sim card proveider telepon selular".

Handphone atau pun sim card bukalah barang mahal lagi yang siap dikonsumsi ,meskipun harganya bisa mencapai jutaan tidak dipermasalahkan. Sedangkan kebutuhan primer berupa pangan,sandang dan papan menjadi sesuatu yang terpinggirkan. Jika ditanya di kalangan menengah ke atas jelas jawabnnya mereka bisa berimbang. Tapi kelas menengah ke bawah jawabannya bisa mendua .Kenapa mendua ? karena barang sekunder seperti telepon selular juga sudah menjadi kebutuhan wajib buat mereka. Harga yang biasnya diterapkan oleh perusahaan telepon dan perusahaan provider memudahkan konsumen untuk memilih handphone atau sim card yang mereka inginkan. Masalah pulsa jelas yang ke dua .Sedangkan tariff yang berlomba-lomba masih diperangkan tetap menjadi acuan konsumen. Konsumen menjadi konsumtif sekarang rendahkah daya beli konsumen.

Jika kembali ke bagaimana teori konsumsi dan kebutuhan tersebut,jika saja semua orang Indonesia sadar dan bisa memilih menyelamatkan ekonomi Indonesia terlebih dahulu baru ekonomi perusahaannya dan ekonomi diri-nya atau apa apun itu saya yakin sebuah debat narsis tidak akan terjadi,siapa yang ingin menjadi pahlawan,dan siapa yang hanya bermulut besar akan tersadar tentang betapa besarnya sebuah arti nurani untuk kehidupan bersama bangsa Indonesia. 


\section{Hubungan Terbalik Riba dengan Sedekah}

Riba secara bahasa bermakna: ziyadah (tambahan). Dalam pengertian lain, secara linguistik, riba juga berarti tumbuh dan membesar. Secara umum, riba berarti pengambilan tambahan dari harta pokok atau modal secara batil, baik dalam transaksi jual-beli maupun pinjam-meminjam yang bertentangan dengan prinsip muamalah dalam Islam. Allah SWT menyebutkan dalam Al-Qur'an:

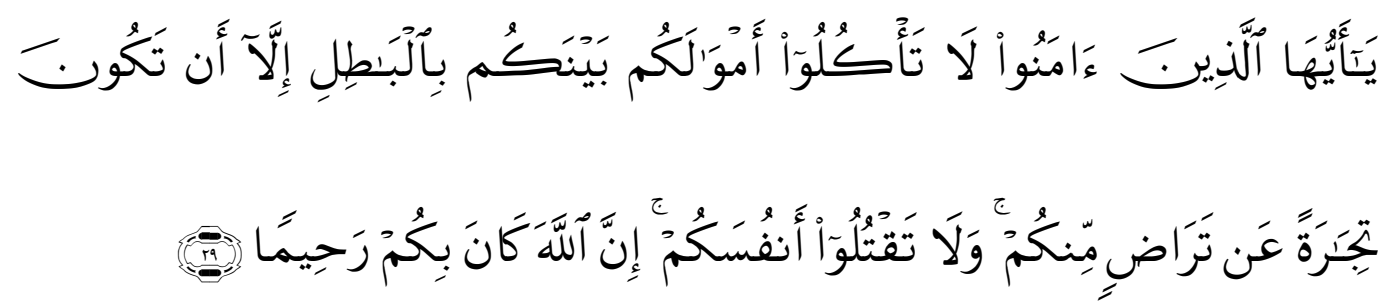

Artinya : "Hai orang-orang yang beriman, janganlah kamu saling memakan harta sesamamu dengan jalan yang batil..." (An-Nisaa': 29)

Sejalan dengan pengertian diatas, Ibnu Arabi dan Imam Sarakhsi menyebutkan bahwa Riba adalah penambahan atas harta pokok, tanpa adanya suatu padanan atau transaksi penyeimbang yang dibenarkan syari'ah atas penambahan itu. Maksud transaksi penyeimbang ini adalah transaksi bisnis atau komersial yang melegitimasi adanya penambahan tersebut secara adil. Seperti dalam transaksi sewa, si penyewa membayar atas manfaat sewa yang dinikmati dan karena menurunnya nilai ekonomis barang sewaan setelah dipakai. Demikian juga dalam proyek bagi hasil, para peserta berhak mendapat keuntungan karena disamping menyertakan modal juga turut menanggung kemungkinan resiko.

Lain halnya dalam transaksi konvensional, simpan pinjam dananya mengambil tambahan dalam bentuk bunga tanpa adanya suatu penyeimbang yang diterima si peminjam kecuali kesempatan dan faktor waktu yang berjalan selama proses peminjaman tersebut. Yang tidak adil disini adalah si peminjam diwajibkan untuk harus mutlak selalu, tidak boleh tidak dan pasti untung dalam setiap penggunaan kesempatan tersebut. Imam Nawawi menyebutkan bahwa salah satu bentuk riba yang dilarang Al-Qur'an dan As-Sunnah adalah penambahan atas harta pokok karena unsur waktu. Dalam dunia perbankan hal tersebut dikenal 
dengan bunga kredit sesuai lama pinjaman. Bunga sendiri dalam undang-undang Romawi berarti potongan yang diberikan akibat kerusakan atau kerugian yang ditanggung si pemberi hutang akibat kegagalan peminjam untuk mengembalikan pinjaman pada saat yang ditentukan. Dalam istilah lain bunga memiliki arti sebagai memiliki arti sebagai harga atau kompensasi atau ganti rugi yang dibayarkan untuk penggunaan uang selama suatu jangka waktu. ${ }^{4}$

Secara garis besar, M. Syafi'i Antonio ${ }^{5}$ mengelompokkan riba menjadi dua, yaitu riba utang-piutang dan riba jual-beli. Kemudian keduanya terbagi menjadi:

1. Riba Qardh, yaitu suatu manfaat atau tingkat kelebihan tertentu yang disyaratkan terhadap yang berutang.

2. Riba Jahiliyyah, yaitu utang yang dibayar lebih dari pokoknya karena pada waktu yang ditetapkan si peminjam tidak mampu membayar utangnya. Hal ini seperti yang disebutkan oleh Qatadah, Zaid bin Aslam dan Ahmad bin Hanbal.

3. Riba Fadhl, yaitu pertukaran antarbarang sejenis dengan kadar atau takaran yang berbeda, sedangkan barang yang dipertukarkan itu termasuk dalam jenis barang ribawi.

4. Riba Nasi'ah, yaitu penangguhan penyerahan atau penerimaan jenis barang ribawi yang dipertukarkan dengan jenis barang ribawi lainnya. Riba ini muncul karena adanya perbedaan, perubahan atau tambahan antara yang diserahkan saat ini dan yang diserahkan kemudian.

Para ahli figh Islam telah membahas masalah riba dan jenis barang ribawi dengan panjang lebar dalam kitab-kitab mereka. Dalam kesempatan ini akan disampaikan kesimpulan umum dari pendapat mereka yang intinya bahwa barang ribawi meliputi:

1. Emas dan perak, baik itu dalam bentuk uang maupun dalam bentuk lainnya.

2. Bahan makanan pokok, seperti beras, gandum dan jagung, serta bahan makanan tambahan, seperti sayur-sayuran dan buah-buahan. 
Dalam kaitannya dengan perbankan syari'ah, implikasi ketentuan tukarmenukar barang ribawi dapat diuraikan sebagai berikut.

1. Jual beli antara barang-barang ribawi sejenis hendaklah dalam jumlah dan kadar yang sama. Barang tersebut pun harus diserahkan saat transaksi jual beli. Misalnya rupiah dengan rupiah hendaklah Rp. 5.000,00 dan Rp. 5.000,00 dan diserahkan ketika tukar menukar.

2. Jual beli antara barang-barang ribawi yang berlainan jenis diperbolehkan dengan jumlah dan kadar yang berbeda, dengan syarat barang diserahkan pada saat akad jual beli. Misalnya, Rp. 9.000,00 dengan 1 dollar Amerika

3. Jual beli barang ribawi dengan yang bukan ribawi tidak disyaratkan untuk sama dalam jumlah maupun untuk diserahkan pada saat akad. Misalnya, mata uang dengan pakaian.

4. Jual beli antara barnag-barang yang bukan ribawi diperbolehkan tanpa persamaan dan diserahkan pada waktu akad, misalnya pakaian dengan barang elektronik. Sekarang bayangkanlah suatu keadaan dimana:
a. Orang tidak mau bekerja mencari pendapatan
b. Praktik riba menjadi tradisi di masyarakat
c. Zakat wajib dilaksanakan

Dalam keadaan ini berarti sumber pendapatan masyarakat hanya dari riba saja, dan tidak ada sumber pendapatan lain. Dari keadaan ini dapat digambarkan tiga kombinasi utility function yang disebut indiference curve atau IC dengan budget line. 


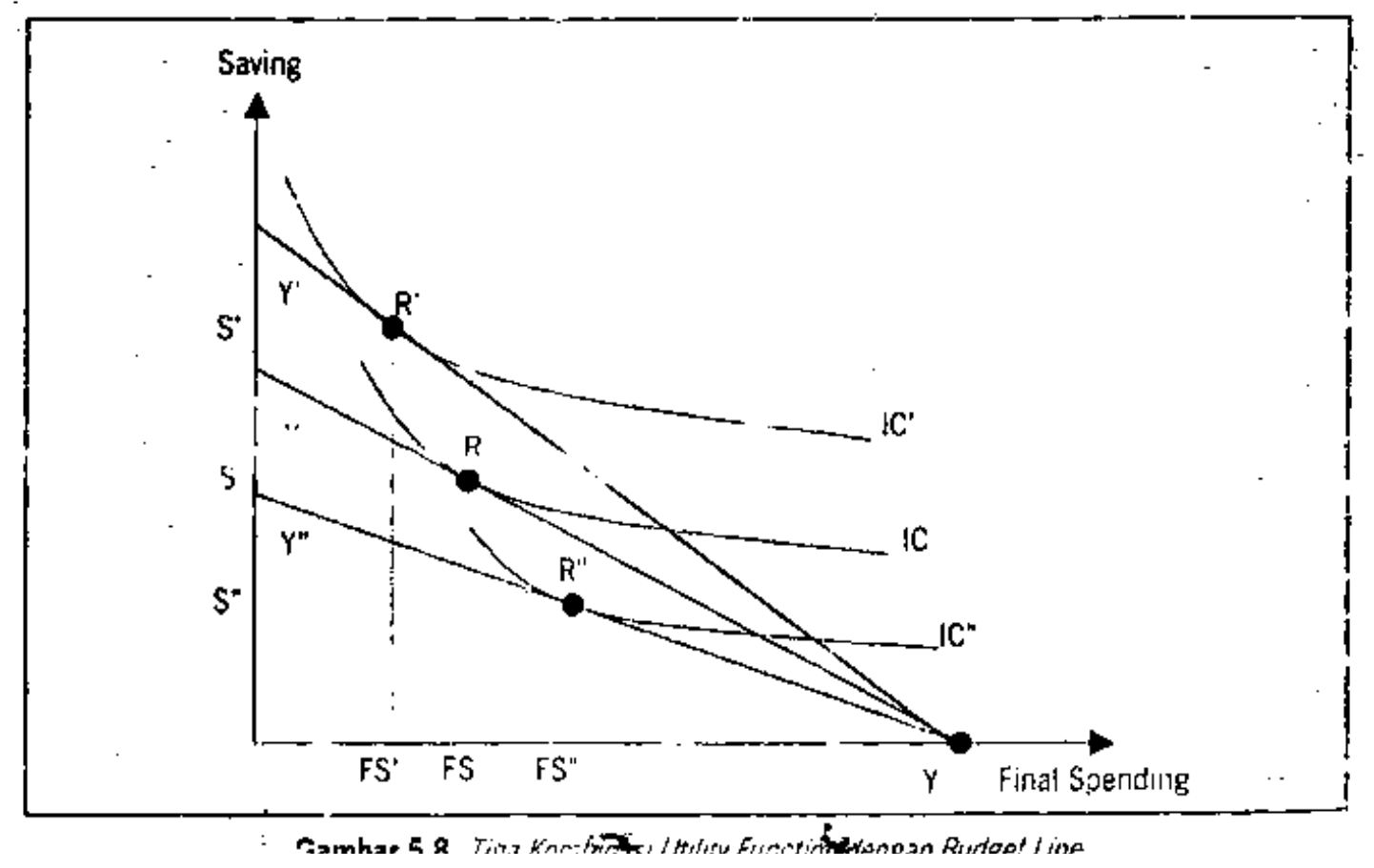

\section{Kasus 1}

Budget line YY menunjukkan keadaan di mana: ${ }^{6}$

1. Orang tidak mau memakan riba yang juga berarti tambahan pendapatannya nihil secara matematis ditulis: $\mathrm{Y}_{\mathrm{t}}=\mathrm{Y}_{\mathrm{t}+1}$ riba, di mana riba $=0$, sehingga $\mathrm{Y}$ ${ }_{\mathrm{t}+1}=\mathrm{Y}_{\mathrm{t}}$;

2. Orang tidak mengeluarkan zakat atas hartanya. Bila ia telah mengeluarkan zakatnya ketika menerima pendapatan, maka ia tidak mengeluarkan zakat lagi pada periode pertama. Atau dengan kata lain $\mathrm{Y}_{\mathrm{t}}$ adalah pendapatan setelah zakat (income after zakat).

Titik optimal terjadi pada persinggungan budget line dengan indifference curve yaitu pada titi R, di mana tingkat konsumsi dan infaknya adalah sebesar FS. Kasus 2

Budget line YY menunjukkan keadaan dimana: ${ }^{7}$

1. Orang mau memakan riba yang juga berarti tambahan pendapatannya positif. Secara matematis ditulis: $Y_{t}=Y_{t}+$ riba, dimana riba $>0$, sehingga $Y_{t-1}>Y_{t}$

2. Orang tidak mengeluarkan zakat atas hartanya, dalam hal ini zakat atas kenaikan hartanya akibat riba. 
Titik optimal terjadi pada persinggungan budget line dengan indeferense curve, yaitu pada titik $\mathrm{R}$, dimana tingkat konsumsi dan infaknya adalah sebesar FS.

Dibandingkan dengan kasus 1 yang tidak ada riba, maka kasus 2 ini mengahasilkan tingkat FS yang lebih kecil dari pada FS (FS<FS). Jadi dengan dibolehkannya riba ternyata terjadi penurunan final spending. Dari kedua final spending, yaitu konsumsi (C) dan infak, maka yang paling mungkin turun adalah konponen infak. Hal ini disebabkan karena kecenderungan orang untuk mempertahankan tingkat pendapatan tertentu, sedangkan komponen infak cenderung variabel untuk tingkat pendapatan tertentu. Sehingga kita mendapatkan hubungan terbali (inverse relationship) antara riba dengan infak :

$$
\text { Infak }=\mathrm{f}(\mathrm{riba})
$$

Semakin besar riba, semakn kecil infak, semakin kecil riba, semakin besar infak. Dalam suatu masyarakat dimana riba begitu telah meraja lela, maka tingkat infaknya akan kecil bahkan kadangkala orang berusaha menghindari membayar zakat yang memang merupakan kewajibannya.

\section{Hubungan Terbalik Saving Ratio dengan Final Spending}

Konsumsi merupakan alat untuk mencapai falah. Monzer khaf6 memperkenalkan final spending (FS) sebagai variabel standar konsumen muslim dalam melihat kepuasan optimum. Kahf mengikutkan variabel zakat sebagai variabel yang menjadi keharusan dalam sistem perekonomian islam. Khaf berasumsi bahwa zakat merupakan kewajiban bagi para muzakki (golongan yang hartanya mengenai nisab sehingga di wajibkan zakat atasnya). Dengan demikian zakat tidak masuk final spending. Final spending dalam seorang individu muslim dalam analisa dua periode menurut khaf adalah sebagai berikut:

$$
\begin{aligned}
& \mathrm{FS}=(\mathrm{Y}-\mathrm{S})+(\mathrm{S}-\mathrm{Sz}) \\
& \mathrm{FS}=(\mathrm{Y}-\mathrm{s} \mathrm{Y})+(\mathrm{sY}-\mathrm{zs} \mathrm{Y}), \mathrm{atau} ; \\
& \mathrm{FS}=\mathrm{Y}(1-\mathrm{zs})
\end{aligned}
$$

Di mana; FS = final spending, $\mathrm{Y}=$ pendapatan, $\mathrm{S}=$ total tabungan, $\mathrm{s}=$ presentase $\mathrm{Y}$ yang di tabung dan $\mathrm{z}=$ presentase zakat. Terlihat bagaimana korelasi 
negatif antara s dan FS, semakin tinggi s semakin kecil FS. Sehingga di dapatkan maksimum kepuasannya berdasarkan tingkat kekayaan dan jumlah pendapatan:

$\operatorname{Max} \mathrm{U}=\mathrm{U}(\mathrm{FS}, \mathrm{s})$

subject to; FS $+\mathrm{S}=\mathrm{Y}$ dan $\mathrm{DW}=\mathrm{S} \geq \mathrm{z}(\mathrm{W}+\mathrm{S})$

Di mana: $\mathrm{U}=$ kepuasan konsumen, $\mathrm{W}=$ Kekayaan konsumen dan $\mathrm{D}=$ time derivative (turunan waktu). Model di atas merupakan gambaran yang ada pada golongan muzakki.

Berdasarkan kemampuan ekonominya masyarakat dapat di bagi menjadi 3 golongan; pertama, golongan masyarakat pembayar zakat atau muzakki. Kedua, golongan penerima zakat atau mustahik. Ketiga golongan masyarakat non muzakki dan mustahik atau kita sebut sebagai middle income.

Golongan Muzakki:

$\mathrm{FS}=\mathrm{Y}-\mathrm{S}$

$\mathrm{FS}=\mathrm{Cz}-(\mathrm{Zy}+\mathrm{In}+\mathrm{Sh}+\mathrm{Wf})$

Di mana; $\mathrm{Cz}=$ total konsumsi golongan muzakki, $\mathrm{Zy}=$ zakat pendapatan, In = infak, Sh = Shadaqah, $\mathrm{Wf}=$ wakaf. Pada model di atas di asumsikan bahwa zakat bersumber dari pendapatan. Dapat di sebutkan bahwa para muzakki mampu untuk mengeluarkan zakat, infak-shadaqah, serta memberikan wakaf.

Golongan mustahik:

$\mathrm{FS}+\mathrm{S}=\mathrm{Y}$ S Mustahik $=0$ dan $\mathrm{Y}=0$ atau $\mathrm{Y}<\mathrm{Co}$, maka

1. $\mathrm{FS}=\mathrm{ZZ}=\mathrm{Co}$, atau;

2. $F s=Y+Z Y+Z=C o$

Di mana: $\mathrm{Co}=$ konsumsi kebutuhan pokok, $\mathrm{Y}=$ pendapatan, $\mathrm{Z}=$ zakat yang di terima. Pada model pertama terlihat bahwa konsumsi sepenuhnya bersumber dari zakat. Artinya sumber konsumsi golongan mustahik ini termasuk kategori fakir, ibnussabil dan fisabilillah. Sedangkan pada golongan yang kedua meliputi mustahik kategori miskin karena belum dapat memenuhi kebutuhan pokoknya sehingga harus di penuhi oleh zakat. Pada kondisi ini final spending melebihi tingkat pendapatan. Menurut Imam Ghazali distribusi zakat hendaknya sebesar kebutuhan mustahik saja7. Artinya zakat yang di distribusikan pada 
golongan mustahik hendakya untuk kebutuhan primer. Jadi Final SpendingMustahik sebesar kebutuhannya.

Golongan Middle income:

$\mathrm{FS}=\mathrm{Y}-\mathrm{S}$

$\mathrm{FS}=\mathrm{Cm}+\mathrm{In}+\mathrm{Sh}$

Di mana: $\mathrm{Cm}=$ total konsumsi golongan middle income, $\mathrm{In}=$ infak, $\mathrm{Sh}$ = shadaqah. Golongan Middle income ini dapat memenuhi kebutuhan primernya dan masih memiliki kemampuan untuk mengonsumsi barang sekunder. Meskipun begitu kekayaannya belum mencapai nisbah sehingga untuk mencapai final spendingnya golongan ini mengeluarkan shadaqah atau infak.

Dengan demikian dapat di simpulkan bahwa zakat pada golongan muzakki akan mengurangi final spendingnya. Hal ini bertolak belakang dengan golongan mustahik di mana golongan ini mampu meningkatkan final spendingnya hingga sebatas untuk memenuhi kebutuhan primernya. Dengan demikian dapat di katakan bahwa zakat merupakan instrumen yang efektif dalam meningkatkan konsumsi masyarakat muslim dan salah satu cara untuk menumpuk dan meningkatkan pahala menuju falah (kebahagiaan dunia dan akhirat).

Untuk melihat hubungan antara Saving dan Final Spending, kita akan melihatnya pada Final Spending dalam periode pertama dari periode kedua. Total Final Spending pada dua periode tersebut final spending periode pertama ditambah final spending periode kedua, atau secara metematis. ${ }^{8}$

$\mathrm{FS}=\mathrm{FS}_{(\mathrm{t}=1)}+\mathrm{FS}_{(\mathrm{t}=2)}$

Dimana :

$\mathrm{FS}_{(\mathrm{t}=1)}=\mathrm{Y}-\mathrm{S}$

$\mathrm{FS}_{(\mathrm{t}=2)}=\mathrm{S}_{1}-\mathrm{ZS}_{1}$

$\mathrm{Zs}_{1}$ adalah besarnya zakat pada periode kedua, zakat pada periode dua hanya didasarkan pada besarnya jumlah tabungan periode pertama $S_{1}$.

Karena $S_{1}=S_{1}$

Maka dapat ditulis :

$$
\begin{aligned}
\mathrm{FS}_{\text {total }} & =\mathrm{FS}_{(\mathrm{t}=1)}+\mathrm{FS}_{(\mathrm{t}=2)} \\
= & \left(\mathrm{Y}_{1}-\mathrm{S}_{1}\right)+\left(\mathrm{S}_{1}-\mathrm{Zs}_{1}\right) \\
= & \left.\mathrm{Y}_{1}-\mathrm{s} \mathrm{Y}_{1}\right)+\left(\mathrm{Sy}_{1}-\mathrm{Zsy}_{1}\right)
\end{aligned}
$$




$$
=\mathrm{Y}_{1}(1-\mathrm{zs})
$$

Dari persamaan ini terlihat bahwa komponen zs bertanda negatif. Ini menunjukkan adanya hubungan terbalik antara final spending dengan saving ratio "s" sedangkat zakat rate 'z" tetap besarannya. Semakin besar "s" maka semakin kecil FS; sebaliknya semakin kecil '-s" maka semakin besar FS.

Secara grafis hal ini dapat digambarkan dengan kurva $\mathrm{Ys}_{1}, \mathrm{Ys}_{2}$, dan $\mathrm{YS}_{3}$. Kemiringan (Slope) dari ketiga kurva tersebut tidak berbeda yaitu $-\{(1-$ $z) / 1\}$

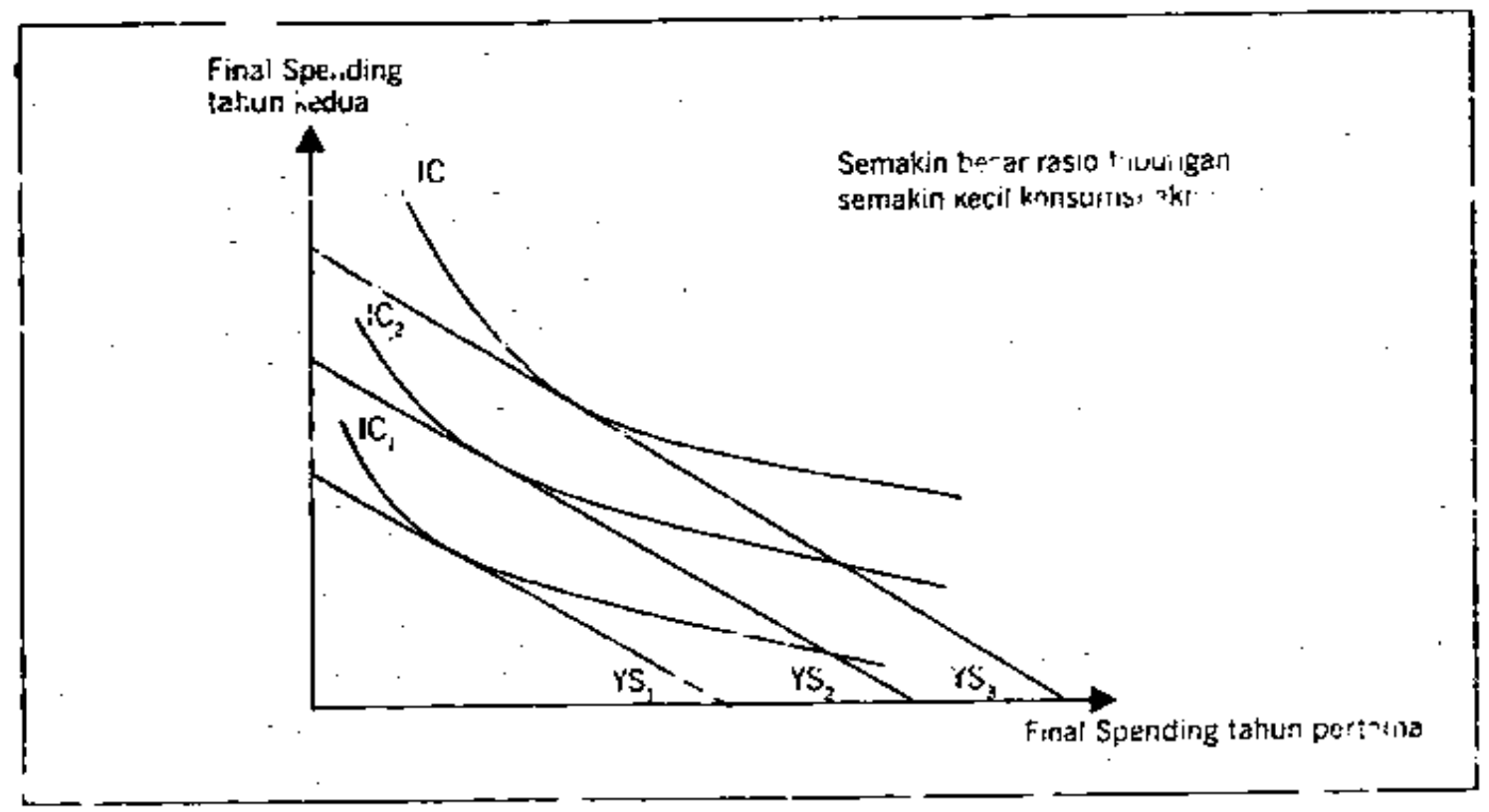

Gambar 5.10. riwungan Tabungan dan konsumsitith

Untuk mudahnya, bayangkanlah kasus 3, yaitu keadaan dimana tidak ada sumber tambahan pendapatan dan wajib mengeluarkan zakat.

Dalam keadaan seperti itu, semakin besar saving yang dilakukan maka akan semakin besar zakat yang wajib dibayar, padahal tidak ada tambahan pendapatan $\left(Z_{1}>Z_{2},>Z_{3}\right.$ karena $\left.s_{1}>s_{2}>s_{3}\right)$. Sehingga hartanya akan habis termakan oleh zakat. ${ }^{10}$ Itu sebabnya secara grafis digambarkan tingkat indifenrense $\mathrm{I}_{1}<\mathrm{I}_{2}<\mathrm{I}_{3}$. Pada saving ratio terbesar yaitu $\mathrm{s}_{3}$, maka indeference curve berada pada tingkat terendah. ${ }^{11}$

Dengan asumsi bahwa final spending pertama dan final spending periode kedua adalah batang normal (normal goods), maka final spending dikedua periode akan lebih besar semakin kecil saving ratio. 
Dalarn pendekatan model keseimbangan pendapatan nasional, zakat, infak dan shadaqah dapat dijelaskan melalui model maslahat/kesejahteraan umat manusia yang lebih luas. Dalam ekonomi konvensional, keseimbangan pendapatan nasional:

$\mathrm{Y}=\mathrm{C}$

Dimana $\mathrm{Y}=$ pendapatan dan $\mathrm{C}=$ konsumsi

Sedangkan dalam ekonomi islam,

$\mathrm{Yi}=\mathrm{Cd}+\mathrm{Ca}$

dimana :

$\mathrm{Yi}=$ pendapatan nasional dalam ekonomi islam

$\mathrm{Cd}=$ konsumsi untuk kepentingan dunia

$\mathrm{Ca}=$ konsumsi untuk kepentingan akhirat, yang terdiri dari konsumsi zakat $(\mathrm{Cz})$

ditambah dengan konsumsi infak dan sadaqah (Cis), $\mathrm{Ca}=\mathrm{Cz}+\mathrm{Cis}$

Sebagai contoh jika diasumsikan bahwa fungsi konsumsi $\mathrm{C}=25+0,75 \mathrm{Y}$, di mana dengan zakat sebesar 2,5\% ditambah infak dan shadaqah. sebesar 2,5\% justru akan meningkatkan pendapatan nasional. Secara. matematis efektifitas zakat, infak dan sadaqah dapat dibuktikan melalui persamaan keseimbangan pendapatan nasional.

a. Dalam ekonomi k.onvensional keseimbangan terjadi pada saat $\mathrm{Y}=\mathrm{C}$ $\mathrm{Y}=25+0,75 \mathrm{Y}$

$\mathrm{Y}-0,75 \mathrm{Y}=25>>\mathrm{Y}=100$ (keseimbangan)

Berikut dibawah ini contoh dari (The law of Diminishing marginal utility) :

Dengan memperhatikan tingkat utilitas yang di peroleh andi dari meminum segelas air putih setelah melakukan olahraga berat

\begin{tabular}{|c|c|c|}
\hline Jumlah gelas & Utilitas total & Utilitas marginal \\
\hline 1 & 12 & 12 \\
\hline
\end{tabular}




\begin{tabular}{|c|c|c|}
\hline 2 & 22 & 10 \\
\hline 3 & 28 & 6 \\
\hline 4 & 32 & 4 \\
\hline 5 & 34 & 2 \\
\hline 6 & 34 & 0 \\
\hline
\end{tabular}

- Gelas pertama belum dengan menghilangkan dahaga andi sepenuhnya sehingga tambahan segelas air putih berikutnya masih akan meningkatkan kepuasan total andi,perhatikan bahwa utlitas total yang di peroleh andi dari meminum segelas air putih terus bertambah sampai dengan gelas ke 5 sedangka gelas ke 6 memberikan tingkat utilitas yang sama dari gelas sebelumnya.

- Makin banyak air yang diminum,kepuasan marginal tiap-tiap gelas berikutnya menurun,(andi semakin kenyang )sehingga tambahan segelas air putih memberikan kepuasan yang semakin sedikit.

Berikut dibawah ini faktor pengaruh tingkat konsumsi dan tabungan :

a. Distribusi pendapatan nasional

b. Banyaknya kekayaan masyarakat dalam bentuk alat likuid

c. Pendapatan akan diterima dimasa yang akan datang (expected income)

d. Jumlah penduduk

e. Pendapatan tertinggi yang pernah di capai pada masa lampau

f. Harapan/ecpectasi masyarakat akan adanya perubahan harga

g. Sruktur pajak

h. Sikap masyarakat terhadap kehematan (attitude toward thrift)

i. Selera

j. Faktor sosial ekonomi

k. Keuntungan/kerugian kapital(windfall Gain)

1. Tingkat Bunga (Rate OF interest) 


\section{Kesimpulan}

Sekarang bayangkanlah suatu keadaan dimana :

1. Orang tidak mau bekerja mencari pendapatan

2. Praktik riba menjadi tradisi di masyarakat

3. Zakat wajib dilaksanakan

Dalam keadaan ini berarti sumber pendapatan masyarakat hanya dari riba saja, dan tidak ada sumber pendapatan lain.

Dari keadaan ini dapat digambarkan tiga kombinasi utility function yang disebut indiference curve atau IC dengan budget line.

Untuk melihat hubungan antara Saving dan Final Spending, kita akan melihatnya pada Final Spending dalam periode pertama dari periode kedua. Total Final Spending pada dua periode tersebut final spending periode pertama ditambah final spending periode kedua, atau secara metematis.

$\mathrm{FS}=\mathrm{FS}(\mathrm{t}=1)+\mathrm{FS}(\mathrm{t}=2)$

Dimana :

$\mathrm{FS}(\mathrm{t}=1)=\mathrm{Y}-\mathrm{S}$

$\mathrm{FS}(\mathrm{t}=2)=\mathrm{S} 1-\mathrm{zS} 1$

Zs1 adalah besarnya zakat pada periode kedua, zakat pada periode dua hanya didasarkan pada besarnya jumlah tabungan periode pertama S1. 


\section{Endnotes:}

${ }^{1}$ Mustafa Edwin Nasution, dkk. Pengenalan Eksklusif Ekonomi Islam. (Jakarta: Kencana Prenada Media Group, 2007), hal. 85.

${ }^{2}$ Adiwarman A. Karim. Sejarah Pemikiran Ekonomi Islam Edisi Ketiga. (Jakarta: PT. RajaGrafindo Persada, 2012), hal. 364

${ }^{3}$ Mustafa Edwin Nasution, dkk. Op.Cit. 87

${ }^{4}$ Hosen, Ir. H. M. Nadratuzzaman dan tim penulis. 2007. Menjawab Keraguan Umat Islam terhadap Bank Syari'ah. Jakarta: PKES Publishing. hlm 21.

${ }^{5}$ Syafi'i Antonio, Muhammad. 2001. Bank Syari'ah: Dari Teori ke Praktek. Jakarta: Gema Insani Press. hlm. 41.

${ }^{6}$ Adiwarman A. Karim.2008. Ekonomi Mikro Islam. Jakarta : PT. Grafindo Persada. Hlm. 92

${ }^{7}$ Ibid. Hlm. 92

${ }^{8}$ Adiwarman A. Karim.2008. Ekonomi Mikro Islam. Jakarta : PT. Grafindo Persada. Hlm. 95

\footnotetext{
${ }^{9}$ Ibid. Hlm. 96

${ }^{10}$ Ibid. Hlm. 96

${ }^{11}$ Ibid. 96
}

\section{DAFTAR PUSTAKA}

Adiwarman A. Karim.2008. Ekonomi Mikro Islam. Jakarta : PT. Grafindo Persada.

Adiwarman A. Karim. Sejarah Pemikiran Ekonomi Islam Edisi Ketiga. Jakarta: PT. RajaGrafindo Persada, 2012.

Mustafa Edwin Nasution, dkk. Pengenalan Eksklusif Ekonomi Islam. Jakarta: Kencana Prenada Media Group, 2007.

Khaf, Monzer. Ekonomi Islam. Yogyakarta : Pustaka Pelajar. 1995

Hosen, Ir. H. M. Nadratuzzaman dan Tim Penulis. 2007. Menjawab Keraguan Umat Islam terhadap Bank Syari'ah. Jakarta: PKES Publishing.

Syafi'i Antonio, Muhammad. 2001. Bank Syari'ah: Dari Teori ke Praktek. Jakarta: Gema Insani Press. 